\title{
COSMOPOLITISMOS COMO DISCURSO COLONIAL E TRADUÇÃO LITERÁRIA
}

\section{COSMOPOLITANISM AS COLONIAL DISCOURSE AND LITERARY TRANSLATION}

Junia Mattos Zaidan ${ }^{1}$

\begin{abstract}
RESUMO: Apresenta-se a hipótese de que o cosmopolitismo opera como potência do discurso regulador da exploração na divisão internacional do trabalho, em que o nacionalismo - proscrito pelo argumento cosmopolitista - tem sido historicamente praticado, de díspares formas, pelos países centrais, com destaque para os Estados Unidos em seu projeto imperialista. A relação da literatura e da tradução literária com os processos transnacionais editoriais face ao cosmopolitismo contemporâneo convoca a análise das determinações dele resultantes, entre as quais, a manutenção dos povos periféricos como corrente auxiliar do circuito multinacional, produzindo a balcanização do conhecimento periférico, ao mesmo tempo que se incute no imaginário desses países dependentes a ilusão da totalidade. Busca-se subsidiar essa hipótese recorrendo-se (1) ao mito do herói Cú-Cullain na literatura traduzida para o irlandês como epítome da construção de um ethos nacionalista anticolonial; (2) ao trabalho da tradutora Else Vieira para assinalar a preponderância da prática tradutória em projetos de afirmação nacional e (3) à discussão de viés cosmopolitista sobre a consagração mundial de Roberto Bolaño como um dos latinoamericanos mais traduzidos no contemporâneo. A perspectiva nacional-popular é apresentada como resposta ao cosmopolitismo, como via para um nacionalismo não burguês, não xenofóbico, não anti-internacionalista, que dê consequência às condições objetivas históricas que nos constituem.
\end{abstract}

PALAVRAS-CHAVE: Tradução e cosmopolitismo. Tradução literária e o nacionalpopular. Nacional-popular. Tradução literária e imperialismo estadunidense.

ABSTRACT: Cosmopolitanism is discussed as part of discourse that regulates exploitation in the international division of labour. In this international dynamics, nationalism is rejected by the cosmopolitanist perspective, though it has been historically practiced by central nations, especially the US in its imperialist project. As part of transnational editorial processes, literature and literary translation call for the analysis of the ways cosmopolitanism determines the subjection of peripheral nations to merely supporting roles in the multinational circuit, thus producing the balkanization of peripheral knowledge, while at the same time instilling in the imagination of dependent countries the illusion of totality. We seek to support this hypothesis by resorting to (1) the myth of the hero Cú-Cullain in the literature translated into Irish as the epitome of the construction of an anti-colonial nationalist ethos; (2) the work of the translator Else Vieira to highlight the preponderance of translation practice in affirmative periphery national projects and (3) the discussion of a cosmopolitanist bias on the worldwide consecration of Roberto Bolaño as one of the most translated Latin Americans in the contemporary

\footnotetext{
${ }^{1}$ Professora do Departamento de Letras da Ufes. Doutora em Linguística, coordena o grupo de pesquisa do CNPq e programa de extensão Observatório de Tradução. E-mail: junia.zaidan @ufes.br.
} 
world. The national-popular perspective is presented as a response to cosmopolitanism, a path towards a non-bourgeois, non-xenophobic, non-anti-internationalist nationalism that addresses the objective historical conditions that have constituted us.

KEYWORDS: Translation and cosmopolitanism. Literary translation and the nationalpopular. National popular politics. Literary translation and US imperialism.

\section{Contextualização}

Por possibilitar o encontro - ou, às vezes, o confronto - entre distintos sistemas de signo, práticas culturais e grupos sociais, a tradução oferece uma perspectiva privilegiada para se analisarem os diversos traços dos cosmopolitismos contemporâneos. Os fluxos culturais transnacionais têm a práxis tradutória como eixo, dando a ver o campo assimétrico em que ocorrem as trocas literárias, bem como a função que cumprem na transferência de capital da periferia para os países centrais. Em face da ampliação, no âmbito dos estudos da tradução, da noção de que o cosmopolitismo seria, a um só tempo, uma realidade empírica objetiva e uma abordagem para descrever essa realidade (BIELSA, 2016), localizamos esforços concertados para criticar a centralidade do Estadonação, sob a alegação de seus efeitos deletérios incidentes sobre o único plano a partir do qual a emancipação seria urdida - o mundial.

Neste breve ensaio, fazemos apontamentos sobre a hipótese de que o cosmopolitismo opera como potência do discurso regulador da exploração, na divisão internacional do trabalho, em que o nacionalismo - proscrito pelo argumento cosmopolitista - tem sido historicamente praticado, ainda que de díspares formas, pelos países centrais, com destaque para o imperialismo estadunidense. A relação direta da literatura e, como nos interessa aqui, particularmente, da tradução literária, com a emergência e consubstanciação de uma abstração como a noção de "povo" convoca a análise das múltiplas formas de cosmopolitismo que não cessam de se atualizar ao longo da história. Como prática em que a realidade da diferença se dá a ver de modo radicalmente inequívoco, a tradução literária, sempre como "recriação ou criação paralela, autônoma e porém recíproca", nas palavras de Haroldo de Campos (1992, p. 35), debruça-se sobre a máquina de criação que é o texto literário, este via tradução desmontado e remontado como "produto acabado numa língua estranha", num corpo linguístico diverso. Tecem-se nesse processo entre o próprio e o alheio trocas inexoravelmente balizadas pelos interesses econômicos e políticos da empreitada 
tradutória. Traduzir literatura - e, amiúde, textos referenciais - consiste em ato engajado, que "sempre incidiu sobre as atividades socioculturais e políticas dos povos, ao longo da história, ora contribuindo com as hegemonias constituídas e a manutenção do status quo, ora fomentando resistências, agenciamentos e lutas por transformação social." (ZAIDAN, 2019, p. 9).

As circunstâncias objetivas da cultura tradutória em nível mundial trazem os seguintes dados, fornecidos por Venuti (2008, p. 11), diretamente relacionados à geopolítica do inglês e à posição dos Estados Unidos como superpotência: o inglês, desde a II Guerra é a língua mais traduzida mundialmente; a porcentagem de literatura estrangeira traduzida para o inglês, que sempre foi inexpressiva (variando entre $2 \%$ e $4 \%$ da produção total na Inglaterra e nos Estados Unidos), reduziu-se ainda mais na primeira década do século XXI para cerca de 1,4\% na Inglaterra e 2,07\% dos livros estrangeiros publicados em inglês nos Estados Unidos. Comparando-se com os 22,9\% e 7,3\% da publicação de livros estrangeiros na Itália e Alemanha, respectivamente, os dados sobre os fluxos transnacionais que a tradução propicia suscitam perguntas sobre o que se quer, afinal, afirmar a partir das expressões "abertura ao outro" [openness to the others], “consciência global”, "fertilização cruzada entre culturas" e superação dos "vínculos locais", todas marcadas na proposta cosmopolitista.

A propósito do cosmopolitismo, seja em sua acepção (1) clássica de cidadania e governança global para além do Estado-nação; (2) como uma expressão global do multiculturalismo liberal, voltado para a criação de uma comunidade política pósnacional; (3) seja como movimentos transnacionais diaspóricos em que os hibridismos constituem seu foco de análise; ou, ainda, (4) em sua versão nomeadamente crítica - sobre a qual nos deteremos - uma alegada realidade em que as diferenças e conflitos seriam reconhecidos, [o cosmopolitismo] estaria, em nossa hipótese, a serviço da ideologia da dependência, uma vez que, na dinâmica de aludir sempre ao cenário internacional, mantém os povos periféricos como uma "uma corrente auxiliar do circuito multinacional, [e] promove a balcanização do conhecimento periférico, enquanto lhe[s] dá o gosto da ilusão da totalidade", como afirma Lucas (1995, p. 14) em seu livro Vanguarda, História e Ideologia da literatura.

Para Antônio Cândido, vigora no Brasil a dialética do localismo e do cosmopolitismo, em movimento pendular, ora de "afirmação premeditata e por vezes 
violenta do nacionalismo literário", ora de "declarado conformismo" caracterizado pela reprodução deliberada dos padrões europeus (CÂNDIDO 1985, p. 109). Ainda que não seja a política de tradução literária o que Cândido está abordando neste ensaio de 1985, sua discussão exibe o seguinte ponto de toque com aquela proposta por Bielsa (2016) em sua defesa de um cosmopolitismo crítico no campo da tradução: enuncia-se a constatação de um cosmopolitismo (ou de uma dialética entre o local e o cosmopolita, nos termos de Cândido) como uma realidade empírica objetiva. Desde sua consolidação como campo disciplinar, figuram na pauta dos estudos da tradução o local, o doméstico e o global, o planetário (para fazer remissão ao conceito de planetaridade de Gaiatri Spivak), mesmo que tenham adquirido, através do tempo, contornos - e designações - díspares.

Silviano Santiago também marcou a crítica nesse campo transcendendo à caracterização do "glocalismo" (localismo / globalismo) para focalizar - e, ademais, posicionar-se a respeito de - duas formas de multiculturalismo. A primeira estaria inscrita na ideia de Estado-nação, considerada por Santiago uma construção "de homens brancos para que todos, indistintamente, sejam disciplinarmente europeizados como eles". A segunda seria, segundo o autor, o processo resultante, por um lado, da migração do campesinato para as grandes cidades pós-modernas e, por outro, da afirmação dos grupos étnicos e sociais que a primeira forma de multiculturalismo subjugou ou subjuga. Nas palavras de Santiago,

\footnotetext{
Ao perder a condição utópica de nação - imaginada apenas pela sua elite intelectual, política e empresarial, repitamos - o estado nacional passa a exigir uma reconfiguração cosmopolita, que contemple tanto os seus novos moradores quanto os seus velhos habitantes marginalizados pelo processo histórico. Ao ser reconfigurado pragmaticamente pelos atuais economistas e políticos, para que se adéqüe as determinações do fluxo do capital transnacional, que operacionaliza as diversas economias de mercado em confronto no palco do mundo, a cultura nacional estaria (ou deve estar) ganhando uma nova reconfiguração que, por sua vez, levaria (ou está levando) os atores culturais pobres a se manifestarem por uma atitude cosmopolita, até então inédita em termos de grupos carentes e marginalizados em países periféricos. (SANTIAGO, 2004, p. 59, 60).
}

Celebrada no meio acadêmico, a posição assumida por Santiago salienta três questões relevantes para nossa reflexão sobre o cosmopolitismo nos estudos da tradução: a premissa de que a unidade nacional seria uma utopia, inscrita, na visão do autor, exclusivamente em uma dinâmica elitista e empresarial; o enfraquecimento do Estadonação como algo supostamente dado e o alegado engajamento dos grupos subalternizados em uma espécie de transnacionalização emancipatória. Em comum com a proposta de 
Bielsa, a formulação de Santiago restringe o enfrentamento da divisão internacional do trabalho imposta pelo imperialismo estadunidense neste estágio avançado do modo de produção capitalista. Como corolário dessa lacuna, sacraliza-se o cosmopolitismo e escanteiam-se formas de pensar a arte e a cultura nacionais fora dos marcos do nacionalismo burguês, que tem o patriotismo ufanista e a xenofobia como potências constitutivas. Limita-se, assim, a possibilidade de se percorrerem veredas teóricas já elaboradas no âmbito do pensamento brasileiro e latino-americano, a exemplo do cientista político, filósofo e tradutor baiano Carlos Nelson Coutinho, que sustentou uma abordagem da arte e da cultura como criação e expressão da visão de mundo nacionalpopular, contra-hegemônica, a partir de Antônio Gramsci (2011), a que retornaremos na última parte deste capítulo. Se, para Santiago, o "confronto no palco do mundo" que a zona de contato estabelece põe em movimento grupos sociais a pleitear um lugar no cenário cosmopolita, para Coutinho, a conflagração se dá, antes de tudo, local e constitutivamente, por meio de processos de transformação "pelo alto" (a exemplo da abolição, da proclamação da República por ele designadas gramscianamente como "via prussiana", "revolução passiva") que alijaram a participação popular criadora tanto na esfera política quanto cultural, em muito diluindo a densidade de uma produção intelectual e artística que se identificasse ao universo popular de modo a contrapôr-se à cultura elitista ornamental, esta incapaz de forjar uma consciência crítica nacional.

As políticas de tradução se inscrevem, portanto, nesse terreno mais amplo em que pensamos a literatura (e não apenas a tradução literária), a produção cultural, as artes e a economia política como imperativos para compreender o fortalecimento de um ethos cosmopolitista nos estudos da tradução. Portanto, a contrapêlo de Santiago e lançando questionamentos sobre a dialética do localismo-cosmopolitismo de Cândido, buscamos ampliar a reflexão sobre o papel da tradução e sua teorização, como práticas artísticoculturais e políticas que incidem sobre a noção de unidade nacional, encontrando lugar no terreno poroso sobre o qual se assenta o discurso do enfraquecimento do Estado-nação.

\section{Estudos da tradução, cosmopolitismo e estatuto colonial}

O que o campo teórico da tradução tem a oferecer à prática em si da tradução e também às articulações teóricas em torno das questões da sociedade? Em Theories of 
Translation (2013), Jenny Williams apresenta em visão panorâmica os objetivos gerais da área, com alusão à formulação que Cronin fizera uma década antes:

\begin{abstract}
A goal for Translation Theory, as proposed by Cronin is to provide an analytical tool to understand and critique global trends (2003). For Cronin, "translation is central to globalization not only because it enables the spread and exchange of goods, services, people and ideas across the globe but also because the theoretical questioning of the practice of translation provides a method for understanding the processes and practices of globalization. Translation Theory does this by exposing the complexities of language, difference, identity, culture and communication (2003, p. 34-36)" (WILLIAMS, 2013 p. 23).
\end{abstract}

Williams e Cronin explicitam o atrelamento histórico da área às questões transnacionais, que, no contemporâneo, o processo de globalização gera de modo particular em termos de diferença, identidade, cultura, geopolítica etc., sobretudo em face da força cultural, política, econômica e bélica dos Estados Unidos. A compreensão e análise crítica da dinâmica transnacional que a tradução inscreve é potencialmente agenciadora de uma consciência e postura crítica a respeito das cartografias neocoloniais que se estabeleceram via imperialismo estadunidense em relação às nações periféricas. Contudo, a afirmação de Anthony Pym nos anos 90 parece encontrar ainda nesta terceira década do século XXI ressonância nos postulados sobre o cosmopolitismo, nosso objeto de crítica no presente ensaio. No fragmento do artigo em que Pym recupera a noção de equivalência como afirmação da existência social da tradução, ele indica que caberia aos estudos da tradução

to envisage intercultural relationships that presuppose neither sovereignty nor
hegemony; to construct a workable language regime for multicultural empires;
to define the authority of intermediaries and their ethical capacity to intervene;
to work productively with machines; to develop intercultural communities and
transnational training programmes hopefully without paternalistic impositions
southward and eastward (PYM, 1995, p.16).

Ainda que aponte para uma política não impositiva do norte global em relação ao sul e a Ásia, a posição de Pym sobre "impérios multiculturais" e "nem soberania, nem hegemonia" concorre para o apagamento da práxis real, historicamente constituída, que envolve a esmagadora maioria da humanidade: a escravização colonial dos povos do mundo, em sua versão eurocêntrica e ianque, esta última hegemônica desde a II Grande Guerra. O discurso multiculturalista que "assim espera" [hopefully] não haver paternalização por parte do norte, mas intervenção por parte dos povos periféricos acaba operando uma espécie de docilização e sensação de harmonia global, ao mesmo tempo que fortalece o que chamamos no congresso que originou o presente livro de estatuto 
colonial da humanidade, traduzido como o saqueio permanente dos povos, o eterno retorno das formas escravistas e servas de exploração.

A existência mesma da literatura é evidenciada pelo ato tradutório, como já destacou Goethe, sempre citado quando o tema é literatura mundial, malgrado a insuficiência que admitiu ser constitutiva da tradução. Trata-se de prática que abriga em seu seio a contradição de, ao pôr em circulacão textos, ideias, também concorrer para o apagamento da diferença constitutiva entre línguas e grupos culturais. Esse pendor para o apagamento potencial, na hipótese de Bielsa - que, como indicamos, encontra interlocução com o argumento multiculturalista de Santiago - seria superado pelo reconhecimento da existência das diferenças e conflitos. O novo cosmopolitismo, segundo a autora, substituiria suas formas predecessoras, quais sejam, (1) o cosmopolitismo como noção clássica de cidadania e governança global para além do Estado-nação; (2) o cosmopolitismo como expressão global do multiculturalismo liberal, voltado para a criação de uma comunidade política pós-nacional e (3) cosmopolitismo como movimentos transnacionais diaspóricos em que os hibridismos constituem seu foco de análise (BIELSA, 2016, p. 5). Na versão nomeadamente crítica que propõe para atualizar o cosmopolitismo nos estudos da tradução, o olhar cosmopolita, apresentado como uma constatação empírica, uma alegada realidade concreta, significaria abertura para o outro [openness to others], em que uma "consciência global" possibilitaria sublinharem-se as tensões entre noções de local/global; universal/particular. Em diálogo direto com Habermas (2006) e Derrida (2001), a formulação autonomeada pósuniversalista de Bielsa para o cosmopolitismo implica "uma análise crítica da centralidade do Estado-nação na teoria social e a defesa de uma abordagem alternativa em relação à realidade social.” (BIELSA, 2016, p. 2, tradução nossa). Sua proposta coloca "o desenvolvimento de uma esfera pública global no centro da imaginação cosmopolita. O hibridismo cultural, a mistura e interpenetração de tradições locais, nacionais e cosmopolitas também são enfatizadas [...]”. (BIELSA, 2016, p. 7, tradução nossa).

Dois pontos sobre os fragmentos acima merecem comentário, a crítica ao Estadonação e a crença na possibilidade de constituição de uma esfera pública global, que pressupõem-se mutuamente pela seguinte razão, tendo em vista o estatuto colonial da humanidade enunciado anteriormente: na periferia do capitalismo, a noção de esfera pública é uma utopia do ultraliberalismo que, ao menos até recentemente, ainda 
encontrava como entrave o que restou da estrutura do Estado, nos diversos espaços nacionais, para garantir, via produção de uma suposta opinião pública, a chancela para empreender as políticas de transferência de recursos para o setor financeiro, no padrão de acumulação atual. O conceito de esfera pública em Habermas (1998, 2003) refere-se ao espaço em que os atores sociais discutem assuntos públicos de modo a produzir uma opinião pública. Como periferia da esfera política, a esfera pública, numa democracia, cumpriria o papel de tensionar a esfera política a partir do consenso que emergiria das interações realizadas no seu interior, as quais envolveriam, necessariamente, tanto discussão/argumentação, quanto a visibilidade das diversas posições. Gomes (1997) assim sintetiza a definição de Habermas, que baliza a formulação dos cosmopolitismo crítico de Bielsa:

\begin{abstract}
A esfera pública é um âmbito da vida social protegido de influências nãocomunicativas e não-racionais, tais como o poder, o dinheiro e as hierarquias sociais. A pública argumentação que nelas se realiza constringe por princípio os parceiros do debate a aceitar como única autoridade aquela que emerge do melhor argumento. A esfera pública como que impõe uma paridade inicial entre os sujeitos de pretensões até que a sua própria posição se torne discurso; depois disso, há de se submeter apenas às regras internas ao processo de conversação ou debate público. (GOMES, 1997, p. 87).
\end{abstract}

Gomes, contudo, diferentemente de Habermas - que enfatiza a discussão pública (exposição e argumentação) - defende a visibilidade como traço tão preponderante quanto a discussão em si, em face da dependência dos meios (mídia) para a sociabilização das posições (GOMES, op.cit.). Porém, com uma mídia flagrantemente concentrada e historicamente oligárquica nos países de capitalismo periférico, a atuação das elites políticas e econômicas - historicamente conluiadas com o imperialismo estadunidense sempre se deu no sentido de garantir a indisponibilidade de dispositivos e mecanismos de comunicação social que garantissem a real constituição de uma esfera em que, no caso do Brasil, por exemplo, emergisse e ganhasse visibilidade a opinião pública como expressão da diversidade étnica, linguística, política do nosso povo. Se, domesticamente, a clivagem entre a esfera pública (que sequer existe de fato) e a esfera política está a serviço de manter esta última como reduto da ação das elites, difundir a ideia de que, transnacionalmente, o cenário seria diferente por meio das práticas tradutórias é, para dizer o mínimo, nas palavras de David Harvey sobre certas versões do cosmopolitismo, uma "política de infantilização" (HARVEY, 2009, p. 39) dos países subalternizados. 
O cosmopolitismo, mesmo em sua versão denominada crítica, baseia-se em uma racionalidade liberal que precisa ser interrogada para construirmos epistemologias da tradução que não apenas reconheçam (como se define o novo cosmpolitismo) o conflito, mas se engagem contra o sistema que produz as desigualdades que fertilizam esses conflitos; ou seja, epistemologias da tradução que não atenuem, mas agenciem a consciência da opressão imposta pela divisão internacional do trabalho e do estatuto colonial. Nesse sentido, a análise da natureza e potência do Estado-nação no contemporâneo precisa ser feita $d a$ perspectiva periférica, levando em conta, por exemplo, elementos como a estigmatização e bloqueio de nações que afirmam sua soberania e autodeterminação, como Venezuela e Cuba. Se há, portanto, uma "realidade empírica concreta" (para valermo-nos da expressão usada por Bielsa sobre o cosmopolitismo como algo já dado), não é exatamente a de um cosmopolitismo que tenha superado sua vocação homogeneizante e docilizante da revolta subalterna. Se há alguma realidade empírica concreta, reiteramos, é o papel que a tradução sempre desempenhou no fortalecimento da unidade nacional e que, sobretudo desde a II Guerra, diante da imposição dos valores e modos norte-americanos de ser por meio da indústria cultural, amplia-se como terreno que sempre foi de disputa teórica porque política. Uma realidade tão empiricamente concreta, que precisa ser re(a)presentada como se fosse diferente, isto é, há tamanha incidência das políticas de tradução - e ademais do conjunto das políticas ligadas à arte e cultura - no sentido de agenciar fluxos e coletividades para o enfrentamento do imperialismo, que epistemologias como o cosmopolitismo e seus derivados emergem para justamente desempenhar o papel de diluir e dispersar esses fluxos potentes.

\section{Cú-Cullain, Else Vieira e Roberto Bolaño}

Se a tradução faz parte da infraestrutura da globalização, é fundamental questionarmos perspectivas que poderão decantar sua natureza política e reduzi-la a um exclusivo papel de mediação de conflitos, ou seja, se a práxis tradutória prescinde da tarefa de sublinhar, salientar o conflito, a diferença e de fortalecer, como é nossa proposta, a unidade nacional dos povos periféricos, ela se prestará a dar ímpeto à hegemonia internacional cuja expressão é o imperialismo estadunidense. Dentre os inúmeros exemplos que podemos citar sobre a direta relação entre políticas de tradução e a 
formação dos estados nacionais na história, o papel de tradutores na retextualização do mito do herói Cú-Cullain na literatura traduzida para o irlandês é a epítome da tradução como construção de um ethos nacionalista anticolonial, como discutiu Tymoczko (2000) em seu texto sobre tradução e ativismo. A luta pela independência da Irlanda teve, portanto, por meio da tradução literária uma forma de enfrentamento ao imperialismo inglês também pela via cultural e não somente política.

No caso do Brasil, um exemplo emblemático nacional desse caráter engajado da tradução, de fundamental importância para nosso grave momento político atual foi o projeto assinado por Else Vieira ${ }^{2}$, que, em plena ditatura militar brasileira, no ano de 1981, traduziu para o português a tese de René Armand Dreifuss, originalmente intitulada "State, Class, and the Organic Elite: the formation of the entrepreneurial order in Brazil (1961-1965)”, publicada pela Editora Vozes como “1964: A Conquista do Estado: ação poítica, poder e golpe de classe". Tratava a tese de um acerto de contas com a narrativa sobre o período histórico que recobria os anos 60, discursivamente construído pelo regime militar de modo a ocultar sua corrupção endêmica, seu compromisso com as elites financeiras e com o imperialismo estadunidense, bem como seus mecanismos espúrios de controle social, que possibilitaram o silenciamento e invisibilização de diversos grupos, além de tortura e execuções autorizadas pelo Estado. Dreifuss reconstituiu, com bases documentais, fatos e personagens desse período fundamental da história, com o objetivo de "identificar as forças sociais que emergiram na sociedade brasileira com o processo de internacionalização em sua etapa moderna e [de] acompanhar sua intervenção no Estado e na sociedade brasileira" (DREIFUSS, 1980, orelha). Através da tradução que Else Vieira se dedicou a realizar, mesmo diante da força intimidadora do Regime, mesmo em estágio avançado de gravidez e com prazo exíguo para concluir a tarefa (Cf. seu relato em VIEIRA, 2010), foi possível tanto a disseminação de uma contra-narrativa pública sobre nossa história, quanto a produção de arquivo e memória, notadamente imprescindíveis hoje, diante do assombro que o espectro da ditadura nos causa, sobretudo pelo tom a ela laudatório de parcela da sociedade e do próprio presidente Jair Messias Bolsonaro.

\footnotetext{
${ }^{2}$ Além de Else Ribeiro Pires Vieira, também atuaram na tradução da tese "State, Class, and the Organic Elite: The Formation of the Entrepreneurial Order in Brazil (1961-1965)" Ayeska Branca de Oliveira Farias, Ceres Ribeiro Pires de Freitas e Glória Maria de Mello Carvalho.
} 
No âmbito da América Latina, o caso de Roberto Bolaño nos interessa sobretudo por ter sido objeto de estudo de Esperanza Bielsa no livro em que propôs o conceito de novo cosmopolitismo, intitulado Cosmopolitanism and translation: investigations into the experience of the foreign (2016) e, alguns anos antes, em artigo publicado em periódico internacional sobre o autor (BIELSA, 2013). Chileno-mexicano e, tendo, na fase final da vida, se radicado em Barcelona, Roberto Bolaño ocupa a posição de um dos autores latino-americanos mais traduzidos e mais analisados internacionalmente. Sua projeção se dá tanto por suas obras, muitas das quais publicadas postumamente, quanto por sua biografia turbulenta e morte precoce. No livro de 2016, Bielsa dedica-se a demonstrar como a tradução de Roberto Bolaño do espanhol para o francês e para o inglês foi fundamental em sua consagração mundial como escritor, consagração essa caracterizada pela autora como traço do cosmopolitismo cultural. Na publicação anterior, de 2013, argumentara que o reconhecimento internacional de Bolaño teve, além da tradução, o papel fulcral dos Estados Unidos para sua recepção e circulação, lançando críticas ao argumento de que a globalização cultural produziria homogeneizações e afirmando o protagonismo dos Estados Unidos nos processos de consagração de literaturas autônomas e não apenas em sua comercialização. Em face da posição de Casanova (apud BIELSA, 2013, p. 159) sobre a limitação do inglês em dar projeção a literaturas periféricas nos países centrais e diante do argumento de que a autonomia do terreno literário está sob o risco da circulação de uma cultura americanizada que se legitimou através da imitação da cultura autônoma, Bielsa contra-argumenta que a produção em pequena escala de literatura nos Estados Unidos exibe "um grau de diversidade cultural" (p. 159) a ser considerado, assim como as "transformações estruturais na circulação transnacional de obras literárias." Sem especificar quais seriam essas transformações estruturais, a autora prossegue:

A existência de novos romances que logram sucesso internacional não se limita [...] à generalização do cânone popular norteamericano, nem à criação de uma ficção mundial produzida de forma artificial para a circulação internacional. $\mathrm{O}$ caso Bolaño, que conjuga o reconhecimento global com sucesso comercial e elogio da crítica com consagração literária nacional e regional, coloca em questão a distinção simplista e rasa feita em relação a trabalhos autônomos e heterônimos, ilustrando a alteração na dinâmica do poder no território literário internacional, onde os Estados Unidos têm desempenhado uma função sem precedentes no sentido de garantir a visibilidade universal de obras literários. Claro, os Estados Unidos não ‘descobrirarm’ Bolaño [...] Contudo, a tradução de seus livros para o inglês e seu sucesso nos Estados Unidos foram cruciais para sua consagração global póstuma. (BIELSA, 2013, p. 159, tradução nossa) 
Sua defesa do globalismo salienta seu favorecimento da perspectiva do "ganho" (contrastado à "perda") em tradução, que, tendo em Bolaño demonstração alegadamente chave, refuta argumentos de que processos tradutórios imprimiriam um assimilacionismo nos fluxos internacionais, sobretudo em relação ao inglês. Sua abordagem cosmopolita decerto reduz o espaço para a crítica à hegemonia cultural estadunidense e consolida um terreno conceitual de suposta horizontalização dos processos tradutórios, a despeito das estatísticas que mencionamos anteriormente, com base em Venuti (2008). Interessa a essa perspectiva cosmopolita o abandono do que se tornou conhecido como "close reading", prática e conceito ligados ao campo da literatura comparada, que envolvem uma leitura profunda do texto literário, sem aceder à tradução como via exclusiva para a recepção de uma obra. Em linhas gerais, a literatura comparada defrontou-se com o surgimento da “world literature" [literatura mundial] na década de 90, tendo que se posicionar a respeito de alegações de que, enquanto campo disciplinar fadado ao desaparecimento (cf. Death of a Discipline, de Gaiatry Spivak, 2003), a literatura comparada apresentava orientação nacionalista (avaliada negativamente), monolíngue, prescritivista e hermética devido ao especificismo cultural determinado por sua inscrição disciplinar. No debate a respeito dessa disputa entre literatura comparada e literatura mundial, esta última tem sido associada ao reforço da hegemonia do inglês, à exotização de outras culturas, à criação de uma falsa sensação de equivalência entre culturas, fetichizando a aparência de alteridade enquanto apaga a diferença e, por fim, ao processo de comoditização da literatura com objetivos comerciais e econômicos, que o adágio conhecido na área, "Sacrificing depth for breadth" [sacrificando-se a profundidade pela abrangência], de algum modo sintetizaria como seu objetivo expansionista (APTER, 2013). Registre-se a peremptória afirmação de Franco Moretti no ensaio "Conjectures on world literature" de que o antinacionalismo seria a razão de ser para o estudo da literatura mundial universal (e para a existência mesma de departamentos de literatura comparada em universidades). Cosmopolita por natureza, a literatura mundial, seja como conceito ou como dinâmica que se estabeleceu desde os anos 90, demarca nitidamente sua filiação político-ideológica ultraliberal em relação ao que temos discutido sobre os países periféricos na divisão internacional do trabalho. A respeito da afirmação de Moretti, Apter, em sua contumaz crítica à ideia de literatura mundial, assinala: "Porém, como temos visto, quanto mais dizemos haver um cânone mundializando-se de acordo com as balizas estabelecidas por Edward Said, menos consenso temos sobre como realizar essa tarefa. (APTER, 2013, p. 42, tradução nossa). 
Embora não entendamos haver tarefa alguma nesse sentido, destacamos a contribuição de Apter para o debate sobre cosmopolitismo no campo da tradução. Mesmo estabelecendo uma espécie de dicotomia entre o que considera vernacularização/etnocentrismo linguístico de um lado e a cultura cosmopolita de outro (ou seja, uma polarização entre nacionalismos e cosmopolitismos), sua abordagem da literatura mundial fomenta a crítica ao "projeto cosmopolita que se adequa mais a emigrantes privilegiados do que às culturas minoritárias que constituem segundas gerações de imigrantes." (APTER, 2013, p. 158, tradução nossa).

A crítica de Loy (2020) à análise que Bielsa apresenta do caso Bolaño (2013; 2016) subsidia nosso argumento a respeito dos limites do cosmopolitismo para garantir a circulação equânime de fluxos culturais no cenário internacional. O autor aponta a tendência de latinoamericanistas como Bielsa e outros de examinarem não o texto traduzido, a obra em si, mas a recepção e a fortuna crítica dessas obras, tendendo, assim, a presumir a qualidade das traduções, e dando-se a elogios infundados, uma forma do politicamente correto em relação aos tradutores, em face da questão de sua invisibilidade ter se tornado objeto de crítica nos estudos da tradução. O elogio à tradução - ainda que vazio e infundado - cumpriria o papel de "valorizar" o tradutor, ao mesmo tempo apagando, segundo Loy,

\footnotetext{
as características formais - desde a coexistência ou mescla das múltiplas variedades do espanhol, até à infinidade de alusões transculturais e intertextuais [na obra de Bolaño, que] representa um sem número de desafios para qualquer tradução. (LOY, 2020, p. 248, tradução nossa).
}

Sem uma leitura detida [close reading] da própria tradução - à moda da literatura comparada, estaria em xeque, por exemplo, nada menos do que o projeto estético em si da obra, o qual obviamente não se distingue de seu conteúdo. Loy cita Corral, que analisa a tradução de algumas obras de Bolaño para o inglês pelo tradutor Chris Andrews. Dando por certa a qualidade das traduções sem o devido escrutínio, na opinião de Loy, Corral assinala que o eventual questionamento sobre a qualidade da tradução se daria caso algum "nacionalista ou provinciano latinoamericano quisesse reclamar de algo que se perdeu no processo de apropriação, como se a tradução fosse mais que uma arma funcional que permite aos monolíngues ampliar suas leituras." (CORRAL, 2011, apud, LOY, 2020, p. 248, tradução nossa). A provocação de Corral plasma a perspectiva antinacionalista antecipada por Moretti, em diálogo com a proposta cosmopolitista de 
Bielsa (2016), bem como os processos de homogeneização potenciais do cosmopolitismo. Se, por um lado, a tradução é uma realidade tão inexorável quanto desejável, por outro, a teorização que dá contornos às práticas e políticas que se instalam pode, pela via cosmopolitista, ir de encontro ao conhecimento acumulado nesse campo, por exemplo, sobre a irredutibilidade de uma obra literária a processos de transferência (ARROJO, 2007); sobre a intraduzibilidade e, ao mesmo tempo, a traduzibilidade, enquanto impasses filosóficos esgarçados pela tradução literária (mas detectáveis em qualquer tipo de tradução) imporem ao tradutor e ao eixo receptor a dupla dobra [double-bind] de Derrida, conceito que possibilita o reconhecimento da complexidade e não a redução do objeto estético a processos homogeneizantes de interesse do mercado internacional e da hegemonia cultural vigente.

Não é circunstancial que Bielsa saúde a queda do muro de Berlim em 1989 como o evento simbólico da "destruição de fronteiras e emergência de novas formas de solidariedade" (BIELSA, 2010, p. 162). A autora ratifica a posição de Robert Fine, para quem a queda do muro

[...] foi propriamente a marca da emergência de um novo movimento intelectual e político que é, por si só, internacional e situa os direitos humanos, as leis internacionais, a governança global e as relações pacíficas entre estados no centro de sua visão de mundo. Quando falamos hoje de 'novo cosmopolitismo' é esse movimento que temos em mente. (FINE, 2007, p. 1, apud BIELSA, 2010, p. 162)

Evidencia-se, a partir do fragmento acima, a relação direta do novo cosmopolitismo com velhas práticas - coloniais, imperialistas, escravagistas - que se traduzem hoje por meio da doutrina ultraliberal, cujos eixos incluem os acordos internacionais que se estabelecem de modo a satisfazer os interesses estadunidenses; a noção de direitos humanos constitutiva do ideário burguês que denuncia as opressões sem tampouco endereçar como problema o modo de produção que as produz; o enfraquecimento do Estado face ao mercado financeiro e às multinacionais; a determinação de combos de medidas em todas as instâncias da vida social dos países periféricos (Consenso de Washington), que encontraram fiel expressão nas contrarreformas e políticas fiscalistas e de austeridade implementadas por todos os governos brasileiros desde 1989, mesmo os democrático-populares e, por fim, o discurso de relações pacíficas, violento por invisibilizar a opressão infligida aos povos do mundo, sem apresentar qualquer lastro na vida concreta, esta eivada de guerras, revoluções coloridas, golpes e toda forma de intervenção das nações hegemônicas nos países que 
abrigam populações desamparadas, desumanizadas pelas privações que sofrem em relação às riquezas materiais e simbólicas produzidas pelo próprio trabalho.

\section{O nacional-popular como estatuto anticolonial}

Neste ponto, lançamos questões que podem ser fecundas à compreensão de que uma noção como a de cosmopolitismo engendrada no contemporâneo simplesmente atualiza conceitos anteriores, como é necessário ao projeto neocolonial, que também caracterizamos como imperialista. Na obra A ideologia do colonialismo e seus reflexos no pensamento brasileiro, Nelson Werneck Sodré nos lembra que

[...] o imperialismo se apresenta com formulações já diversas, perfeita e nitidamente encadeadas com as anteriores entretanto. Hoje, já é difícil difundir teorias de superioridade de raça, de clima, de posição geográfica. A resistência que elas encontram cresceu de tal maneira que já perderam a efetividade, deixaram de ser úteis aos fins a que se destinavam. Tornou-se imperioso substituí-las por outras, particularmente no campo econômico. Daí assistirmos, agora, à rápida transição delas para novos dísticos. Mas parece perfeitamente claro que os pregadores da inferioridade brasileira quanto à possibilidade de explorarmos as nossas riquezas com os nossos próprios recursos e em nosso próprio benefício, os que acreditam e proclamam que só podemos nos desenvolver com a "ajuda" estrangeira, o que confiam apenas nos capitais externos para fomentar o nosso progresso, são herdeiros diretos daqueles que pregavam a superioridade racial, a superioridade climática, a superioridade geográfica, da parte dos países dominantes. E a nossa consequente inferioridade. (SODRÉ, 1984, p. 10)

É imperiosa (e imperialista) a substituição de velhos conceitos por novos, como afirma Sodré. Qual papel cumpre a disseminação de uma ideia de constatação de horizontalidade e livre circulação de fluxos culturais transnacionais presentes na proposta cosmopolitista e também multiculturalista, quando as condições objetivas da vida contemporânea se constituem da mais cruel e violenta realidade econômica e, assim, humana?

Registre-se, como sinalizamos anteriormente, que na teorização que oferece para os estudos da tradução, Bielsa (2010) adere à formulação de Ulricch Beck, segundo quem o chamado 'nacionalismo metodológico' deve ser substituído pelo 'cosmopolitismo metodológico'. A partir dessa "visão cosmopolita",

[...] o nacionalismo que sempre caracterizou a sociologia e outras ciências sociais, segundo o qual a nação, o Estado e a sociedade são as formas sociais e políticas 'naturais'do mundo moderno, é cego ao cosmopolitismo emergente e às múltiplas identidades e afiliações que transcendem fronteiras nacionais. A 
visão cosmopolita substitui a nacional, abrindo os olhos dos povos para uma realidade cosmopolita já existente. (BIELSA, 2010, p. 162).

O cosmpolitismo deve ser por nós esquadrinhado criticamente justamente porque pressupõe uma pauta antinacionalista. A esse respeito, alguns fragmentos do pronunciamento de George W. Bush, então presidente dos Estados Unidos, por ocasião de uma homenagem às vítimas do 11 de setembro, fornecem respostas a algumas questões que levantamos acima.

We are determined to stand for the values that gave our nation its birth [because] a peaceful world of growing freedom serves America's long term interests, reflects enduring American ideals and unites America's allies. [...] [humanity] now holds in its hands the opportunity to further freedom's triumph over its age-old foes" [...] The US welcomes its responsibility to lead in this great mission. (BUSH, New York Times, 2003, grifo nosso.)

No ano seguinte, durante a convenção nacional do Partido Republicano, afirmou:

I believe America is called to lead the cause of freedom in a new century, I believe that millions in the Middle East plead in silence for their liberty. I believe that given the chance they will embrace the most honorable form of government ever devised by man. I believe all these things because freedom is not America's gift to the world, it is the Almighty's gift to every man and woman in this world.

Quando, no dicurso de posse, ao se reeleger, em 2005, prometeu:

We go forward with complete confidence in the eventual triumph of freedom. Not because history runs on the wheels of inevitability. It is human choices that move events. Not because we consider ourselves a chosen nation. God moves and chooses as he wills [While] history has an ebb and flow of justice, it also has a visible direction, set by liberty and the author of liberty.

O discurso de Bush - que se amoderna nas intervenções de seus sucedâneos, não importando suas filiações ao Partido Democrático ou Republicano - exibe a centralidade da nação, do Estado Americano, inclusive como aquele que liderará, messianicamente o mundo, não apenas as Américas, como enuncia a doutrina Monroe de 1823 (As Américas são dos norteamericanos). Note-se nos fragmentos o movimento retórico que parte dos valores estadunidenses, segue na direção de valores humanos universais e dados pela natureza, para desembocar na alusão ao Todo-Poderoso [Almighty] Deus [God]. Salienta-se a recorrente presença da palavra liberdade [liberty / freedom], historicamente fundamental na base ideológica que sustenta o estatuto colonial da humanidade, este diretamente associado ao parasitismo das classes sociais que vivem dos saqueios dos 
povos por meio de guerras. No caso dos povos latino-americanos há mais de cem anos tornamo-nos o quintal dos EUA.

Que o nacionalismo dos povos periféricos seja tabuizado por quem detém a hegemonia política, econômica e cultural constitui um truísmo bem sintetizado por Karl Marx, que dizia não se espantar com o fato de aqueles que nao entendem como uma nação explora a outra sejam os mesmos que nao entendem como uma classe explora a outra. Nas palavras do argentino Juan José Hernández Arregui, que adensou a discussão latinoamericana sobre a consciência e libertação nacional em um período de expansão violenta do imperialismo ianque,

O que é o imperialismo senão o nacionalismo das potências poderosas? Há dois nacionalismos: um do Estado forte que se anexa ao débil, outro, o nacionalismo dos povos débeis contra a prepotência dos fortes. É uma hipocrisia radical, ainda pintada de amor universal [...] a identificação do fascismo com os nacionalismos dos países dependentes.(ARREGUI, 1957, [s. n.] )

Embora negligenciada por expressiva parcela da intelectualidade brasileira e pelo meio acadêmico, é farta a produção teórica brasileira e latinoamericana sobre nossa dependência e subdesenvolvimento e sua relação com a necessária recuperação de um nacionalismo não burguês, não xenofóbico, não anti-internacionalista, mas que dê consequência às condições objetivas históricas que nos constituem. Em escala global se produz uma riqueza gigantesca, que é apropriada pelos países centrais. Se o desenvolvimento do capitalismo no mundo subalternizado implica a transferência de valor da periferia para o centro, ou seja, na apropriação do excedente pelos países centrais, temos um problema: uma naçao oprime outra. A relação da arte e da cultura com essa realidade é indissociável.

Um mundo sem nacionalismo somente seria possível com o ocaso das nações. É desejável? Certamente, mas é preciso levar em conta que o grande capital não pode prescindir do Estado-nação a seu exclusivo serviço. Portanto, seguirá exorcizando qualquer manifestação de nacionalismo na periferia que impeça $o$ mínimo de controle popular sobre recursos estratégicos da nação, ou seja, minerais, mão de obra, alimentos e, especialmente, fluxos financeiros. É claro que a análise deste fenômeno não deveria ocultar outro dado elementar do mundo modernos: o nacionalismo praticado historicamente pelos países centrais não somente segue intacto como ganhou força nas décadas em que o chamado neoliberalismo foi aplicado sem restrições. Em consequência, tanto na cultura quanto na economia, o nacionalismo realmente destrutivo segue sendo aquele praticado pelos países centrais contra os países periféricos. (OURIQUES, 2015, p. 168). 
A esfera cultural apontada por Nildo Ouriques é questão em que nos deteremos neste final de ensaio a fim de fazer contraponto à formulação cosmopolitista antinacionalista de Bielsa. Para tanto, o conceito de consciência ingênua e consciência crítica propostos pelo filósofo brasileiro Álvaro Vieira Pinto, bem como a vasta discussão que fez sobre a realidade nacional e o desenvolvimento da técnica como determinante para a superação de nosso subdesenvolvimento e dependência são fundamentais. Filósofo e tradutor na periferia do sistema, o autor de Consciência e realidade nacional nos adverte do fato de que "Os países subdesenvolvidos só terão a esperança de alcançar o plano onde se acham os mais adiantados, se não estiverem condenados a repetir o desenrolar histórico que permitiu a estes chegar ao ponto em que se encontram.” (PINTO, 1960, p.84). Na mesma obra, a reflexão de Vieira Pinto subsidia a possibilidade do fortalecimento de um nacionalismo que se solidarize - e articule - com Estados-nação que também encampem a luta pela própria emancipação.

\begin{abstract}
O ascenso histórico de um país, ameaçando romper equilíbrios e relações de dominação, gera um potencial político que não deve ser avaliado em termos puramente econômicos. A expansão nacional, à medida que permite desarticular a composição dinâmica internacional, multiplica o poderio do país em desenvolvimento. Se admitirmos, além disso, que, em momento histórico como o atual, numerosos países da chamada região periférica estão, simultaneamente, em graus variáveis, executando o mesmo tipo de esforço nacional, em consequência do qual se encontram em fase de sensível desenvolvimento, compreenderemos que a reunião deles em um movimento conjunto seria o meio de capitalizar a mais-valia política, disponível em cada um, para uma atuação internacional organizada que lhes daria relevante papel no comando do processo mundial, e de que se valeriam para eliminar os obstáculos que opõem ao seu pleno desenvolvimento os que no momento detêm a supremacia econômica e o poder de arbítrio. (PINTO, 1960, p. 332).
\end{abstract}

Contudo, avançar nesse sentido é tarefa que encontra sérios limites a não ser que se construa, nacionalmente, uma consciência crítica que nos possibilite compreender como a classe parasitária do imperialismo estadunidense retroalimenta, na atualidade, o estatuto colonial da humanidade - problema que não será minimanente equacionado com perspectivas cosmopolitistas, nem tampouco antirrealistas nas Ciências Humanas e nas teorias estéticas; e mesmo no âmbito da produção literária propriamente dita, aí incluídas as políticas de tradução. A elevação da consciência popular é tematizada pelo cientista político, filósofo e imprescindível tradutor baiano Carlos Nelson Coutinho, na introdução do livro Cultura e sociedade (2011).

Em articulação com o pensamento de Antônio Gramsci, Coutinho analisa a história da produção artístico-cultural brasileira identificando, por exemplo, em Lima 
Barreto, Jorge Amado, Graciliano Ramos, Manuel Antônio de Almeida - e também em Caio Prado Jr, Florestan Fernandes e outros teóricos - o "esboço de uma alternativa nacional-popular e democrática para nosso país" (COUTINHO, 2011, p. 11) pelo fato de terem elaborado contumaz crítica ao modelo de modernização "pelo alto", como mencionamos anteriormente, em alusão à "via prussiana" ou "revolução passiva". Fundamental para a formulação do nacional-popular, esse conceito de "via prussiana" possibilita ampliar nossa compreensão do processo de produção intelectual e artísticocultural brasileira que historicamente - ainda que com períodos de exceção, interditou a participação popular crítica e criativa, escamoteando assim processos identificados ao universo popular que poderiam se contrapôr à cultura elitista ornamental, intimista esta incapaz de forjar uma consciência crítica nacional por estar apartada da luta de classes. Com constante advertência para que não se caia na armadilha de um falso "nacionalismo cultural", Coutinho aponta a indissociabilidade da intelectualidade e dos artistas em relação aos processos históricos de transformação da sociedade, uma inalienável organicidade entre a cultura e a política como dialética fundamental para uma nova hegemonia de classe. O nacional-popular, portanto, implica o cultivo de uma consciência e de uma cultura "não elitista, não intimista, ligadas aos problemas do povo e da nação" (COUTINHO, 2011, p. 25), que vetorializam a ruptura com o atual sistema de produção capitalista porque se compromete em garantir

[...] as condições para que os intelectuais comprendam de dentro, como uma exigência de sua própria sobrevivência como produtores de cultura, a necessidade da construção de uma sociedade democrática. A conquista da democracia - de um sistema de organizações culturais aberto e pluralista, apoiado numa sociedade civil autônoma e dinâmica - torna-se a base para o florescimento de uma cultura nacional-popular entre nós mas a elaboração e difusão de tal cultura, contribuindo para a hegemonia dos trabalhadores (do braço e da mente) na vida nacional, é por seu turno um momento ineliminável na conquista, consolidação e aprofundamento da democracia, de uma democracia de massas que seja parte integrante da luta e da construção de uma sociedade socialista em nosso país. (COUTINHO, 2011, p. 33)

O nacional-popular enquanto perspectiva da arte e da cultura não tem um fim em si mesmo, posto que fertiliza o terreno para os trabalhadores avançarem na construção de uma hegemonia de classe. Registre-se a preocupação de Coutinho, em diálogo com intelectuais que pensaram e têm pensado a história de violência que constituiu a dependência e subdesenvolvimento da América Latina, no sentido de que não se traduza a ideia de nacional-popular como um anti-internacionalismo nesse campo, o que ilumina nossa discussão sobre o cosmopolitismo nos estudos tradutórios. Ele afirma: 
[...] esse vínculo com a cultura universal não impõe necessariamente um caráter dependente ou "alienado" à totalidade de nossa cultura. Por um lado, no interior de nossa formação social, há a presença de classes antagônicas, com perspectivas diferentes diante do problema da dependência política e econômica, da subordinação (formal ou real) ao capital mundial; por outro, no seio da cultura universal, surgem correntes ideológicas diversas que refletem no plano das ideias - para nos expressarmos de modo simplificado - o antagonismo entre progresso e reação. Ora, é natural que se formem "afinidades eletivas" entre as classes anticoloniais e anti-imperialistas e as correntes ideológicas progressistas; ou entre os beneficiários da dependência e as correntes reacionárias. [...] me parece justo dizer que, quando "transplantada" para o Brasil por uma classe progressista e anticolonial, uma corrente cultural avançada contribui para formar em nosso país uma consciência social efetivamente nacional-popular, contrária ao espírito da dependência, àquilo que Nelson Werneck Sodré chamou de "ideologia do colonialismo". (COUTINHO, 2011, p. 41)

Portanto, não se exclui nosso vínculo com a cultura universal, pelo contrário, se fortalece desde que essa cultura seja "deglutida" por nossa cultura nacional, que, na perspectiva gramsciana adotada por Coutinho, encara até às ultimas consequências os problemas de nossa formação social e política como indissociáveis do campo da arte e da cultura. A propósito do cosmopolitismo apresentado recentemente nos estudos da tradução, a temática já era amplamente debatida por Coutinho e outros intelectuais que viveram a efervescência revolucionária e anti-imperialista do pré-64. Nesse livro que mencionamos, publicado em 2011 como coletânea de ensaios, em texto datado de 1977 a 1979, Coutinho nos lembra:

Assim, se o nacional-popular é essencialmente um modo de articulação entre os intelectuais e o povo (que faz desses intelectuais - na expressão de Gramsci - "intelectuais orgânicos" das correntes populares), ele não pode ser entendido [...] como algo oposto ao universal, como simples afirmação de nossas pretensas raízes culturais "autônomas" contra a penetração do "cosmopolitismo alienado" etc. Decerto, não se trata de afirmar que tal postura abstratamente cosmopolita não exista entre nós: ela se manifesta sempre que a recepção de uma corrente cultural universal se faz de modo abstrato, sem nenhuma tentativa de concretizá-la e enriquecê-la no confronto com a realidade brasileira. Em palavras mais precisas: há cosmopolitismo abstrato todas as vezes que a "importação"cultural não tem como objetivo responder a questões colocadas pela própria realidade brasileira, mas visa tão somente a satisfazer exigências de um círculo restrito de intelectuais "intimistas". (COUTINHO, 2011, p. 54, grifos nossos)

O autor avança no argumento segundo o qual uma postura cosmopolita" alinha-se a uma cultura elitista e não nacional-popular, posto que a separação que se estebelece em relação ao povo torna certos intelectuais "incapazes de proceder àquela concretização e àquele enriquecimento do patrimônio universal." (COUTINHO, 2011, p. 54) A afirmação do nacional-popular como estatuto anticolonial vai de encontro ao cosmopolitismo que potencialmente coloca os povos periféricos em posição caudatária cultural, política e economicamente. A reflexão de Coutinho contribui para a pesquisa 
nos estudos da tradução e também para a prática da tradução no sentido de reconhecer a inexorável inscrição das práticas culturais -dentre elas a tradução e a teorização - no campo político, seja nacional ou internacionalmente. Não se restringe, como seria próprio de uma visão cosmopolita nos termos criticados neste ensaio, a situar a produção nacional numa relação com o mundo, mas o contrário, situando os fluxos culturais transnacionais com o Brasil, considera as condições objetivas de nossa arte e cultura contemporâneas e aponta o horizonte de emancipação, que jamais poderá prescindir da consciência sobre os territórios, as disputas, as narrativas, as representações e formulações teóricas que concorrem para impedi-la. Essa mesma consciência que o poeta, filósofo e revolucionário cubano José Martí dá a ver no enunciado que epigrafa este capítulo.

\section{Referências}

APTER, Emily. Against world literature. Nova York: Verso, 2013.

ARREGUI, Juan José Hernández. Imperialismo e cultura. Buenos Aires: Edições Continente, 1957.

ARROJO, Rosemary. Oficina de tradução: a teoria na prática. São Paulo: Ática, 2007.

BIELSA, Esperanza. Cosmopolitanism and Translation: investigations into the experience of the foreign. Londres: Routledge, 2016.

BIELSA, Esperanza. Translation and the international circulation of literature: a comparative analysis of the reception of Roberto Bolaño's work in Spanish and English. The Translator, v. 19, n. 2, p. 157-81, 2013.

BIELSA, Esperanza. Cosmopolitanism, translation and the experience of the foreign. Across languages and cultures. N. 11, v. 2, pp. 161-174, 2010.

CALZADA PÉREZ, Maria. Translators and translation studies: scholars as inoculators of resistance. The Translator. v. 13, n. 2, p. 243-269, 2007.

COUTINHO, Carlos Nelson. Cultura e sociedade no Brasil: ensaios sobre ideias e formas. São Paulo: Expressão Popular, 2011. 
DERRIDA, Jacques. On Cosmopolitanism and Forgiveness. Tracução de Mark Dooley. Londres e Nova York: Routledge, 2001.

DREIFUSS, Renè Armand. 1964: A Conquista do Estado - ação política, poder e golpe de classe. Coordenação da tradução por Else Vieira. Petrópolis: Editora Vozes, 1981.

GOMES, Wilson. Esfera pública política e media. Com Habermas, contra Habermas. Anais do VI Encontro anual da COMPÓS, Unisinos, 1997.

HABERMAS, Jürgen. The divided west. Tradução de C. Cronin. Cambridge: Polity, 2006.

HABERMAS, Jürgen. Mudança estrutural na esfera pública: investigações quanto a uma categoria da sociedade burguesa. 2.ed. Rio de Janeiro: Tempo Brasileiro, 2003.

HABERMAS, Jürgen. Further Reflections on the Public Sphere, In: Habermas and the Public Sphere, Craig Calhoun (Org), Cambridge, Massachussets, MIT Press, 1996. pp. $421-461$.

HARVEY, David. Cosmopolitanism and the geographies of freedom. Nova York: Columbia University Press, 2009.

LOY, Benjamin. Glotopolíticas literarias entre resistencia y mercado: Bolaño en traducción, la traducción en Bolaño. In: Literatura latinoamericana mundial. GUERRERO, G; LOCANE, Jorge; LOY, Benjamin; MÜLLER, Gesine. Berlin: De Gruyter, 2020. P. 243-264.

LUCAS, Fabio. Vanguarda, História e Ideologia da literatura. São Paulo: Ícone Editora, 1995.

OURIQUES, Nildo. O colapso do figurino francês. 4a ${ }^{\mathrm{a}}$. ed. Florianópolis, Insular, 2015. PINTO, Álvaro Vieira. Consciência e realidade nacional. 1. Vol. Rio de Janeiro: Instituto Superior de Estudos Brasileiros, 1960.

PYM, Anthony. European Translation Studies, Une science qui derange. And Why Equivalence Needn't Be a Dirty Word', TTR 8: 1, 154-76, 1995. 
SANTIAGO, Silviano. O cosmopolitismo do pobre: crítica literária e crítica cultural. São Paulo: Humanitas, 2004.

SODRÉ, Nelson Werneck. A ideologia do colonialismo: seus reflexos no pensamento brasileiro. $3^{\text {a }}$. e. Petrópolis: Vozes, 1984.

SPIVAK, Gaiatry. Death of a discipline. Nova York: Columbia University Press, 2003.

TYMOCZKO, Maria. Translation, Resistance, Activism. Amherst and Boston: University of Massachusetts Press, 2010.

VENUTI, Lawrence. The translator's invisibility: a history of translation, 2a. ed. Londres: Routledge, 2008.

VIEIRA, Else. Growing agency: the labors of political translation. In: TYMOCZKO, Maria. Translation, Resistance, Activism. Amherst and Boston: University of Massachusetts Press, 2010, p. 211-226.

WILLIAMS, Jenny. Theories of Translation. Palgrave Macmillan. Londres, 2013.

ZAIDAN, Junia C. S. de Mattos. Dossiê tradução e transformação social. Percursos Linguísticos. v. 9, n. 21, p. 9-12, 2019. 